\title{
Comparative Analysis of NDVI and Microwave-Derived Soil Moisture for Determining Surface Water in the Cooper Creek Catchment
}

\author{
$\underline{\text { J.Ho }}^{\text {a }}$, D.Ryu ${ }^{\mathrm{a}}$ and J.Costelloe ${ }^{\mathrm{a}}$ \\ ${ }^{\mathrm{a}}$ The University of Melbourne, Parkville, Victoria, 3010 \\ Email: jonho@unimelb.edu.au
}

\begin{abstract}
Arid floodplain ecosystems such as Cooper Creek in Australia are of great national and ecological importance; supporting rural communities as well as significant agriculture, tourism and mining industries. Arid floodplains also contain some of the last remaining untouched wilderness areas. Highly irregular flow regimes create an abundance of naturally varying habitats and environmental conditions, of which contribute to a vast diversity of flora and fauna, resilient and adapted to the harsh conditions yet also extremely vulnerable to diversions from the natural rhythm.

The remoteness, scale and variability of these systems make it difficult to conduct routine monitoring and data acquisition. The Cooper Creek catchment covers an area of almost $300,000 \mathrm{~km}^{2}$, with some reaches of the river swelling to widths of $60 \mathrm{~km}$ during high flows and other reache, more often than not receiving little or no flow.

Remotely sensed data can provide up-to-date information about surface conditions such as soil moisture content, surface water extent and vegetation health among others. Satellite monitoring of flood inundation using optical sensors is often hampered by cloud cover obscuring surface radiations in the visible to infrared ranges. Microwave observations, in spite of coarse spatial resolution of the observations, are able to complement the optical instruments due to the all-weather capability of the microwave radiation sensor. Episodic flood events resulting from rain falling in the upper catchments of Cooper Creek provide a unique opportunity to map the flood inundation using both optical and microwave remote sensing techniques in the same time frame.

We explore the time series of the satellite observations over the Cooper Creek catchment and demonstrate a typical temporal pattern of the optical and microwave signals identifying the presence of surface water from before to after a single flood event. The relationship between these two monitoring techniques was analysed and a common feature was observed in the optical and the microwave signal during the flood event. Soil moisture measurements peaked in concurrence with NDVI reaching its minimum. Groundbased data from gauging points both upstream and downstream of Cooper Creek confirmed the presence of flood waters.
\end{abstract}

This research provides an opportunity not only to compare and analyse these remote sensing techniques but also to observe the hydrological and ecological processes that govern large scale, arid environments during episodic flood events such as flood extent and vegetation response. Understanding these processes can give greater insight into designing future anthroprogenic developments with minimal impact on the surrounding environment.

Keywords: remote sensing, arid, floodplain, surface water, MODIS, NDVI, AMSR-E 


\section{INTRODUCTION}

Large scale, arid environments provide a significant challenge for monitoring and data acquisition involving the spatial and temporal dynamics of their hydrology. Apart from their scale and remoteness, the erratic variability in rainfall and availability of water results in a great variety of environments and land conditions. Remote sensing provides the ability to consistently observe such environments at a range of spatial and temporal resolutions.

This research maps a large flood event in Cooper Creek in Australia using two sources of remote sensing observations to detect surface water. The passive microwave sensor on the Advanced Microwave Scanning Radiometer for the Earth Observing System (AMSR-E) collects information about soil moisture, vegetation water content, and soil/ canopy temperatures. The MODerate Resolution Imaging Spectroradiometer (MODIS), an optical sensor, gathers reflectivities in 36 different wavelengths that can then be used to obtain other observation products of which this research utilises band 1 and 2. Both instruments are onboard the satellite AQUA and have high temporal frequency with each providing observations 1-2 times a day.

The advantages and disadvantages of using optical remote sensing, namely MODIS, in flood mapping and monitoring are well documented by Irimescu et al. (2009), who carried out a flood monitoring and damage assessment on the Danube in Romania. The temporal, spectral and radiometric resolution of MODIS was advantageous in flood mapping, although was limited in its inability to penetrate cloud cover. In fact, cloud cover was commonly found to be a major limiting factor of MODIS, particularly in flood monitoring, due to the large amount of rain often associated with flood events. Alsdorf et al. (2007) and Smith (1997) describe cloud cover as the greatest problem in using visible/infrared bands, prohibiting the view of the Earth's surface. This limitation is a recurring issue in many research papers describing visible/infrared remote sensing, including Smith (1997), Mertes (2002), and Irimescu et al. (2009) so cloud-penetrating microwave sensors are often employed even with their coarse spatial resolution.

A significant advantage of using AMSR-E in floodplain mapping is its limited sensitivity to cloud cover. AMSR-E provides daily brightness temperature observations of microwave radiation emitted from the land surface, which are then used to generate a soil moisture product. Bindlish et al. (2009) used passive microwave remote sensing, also on the Cooper Creek catchment, for flood forecasting purposes. They developed a time series of images from AMSR-E demonstrating the effect of existing soil moisture content on the dynamics of a subsequent flood event. Bindlish et al. (2009) asserted that AMSR-E, even with its poor spatial and temporal resolution, is well suited for large scale hydrological applications, however higher resolution images provided by MODIS and Landsat are preferred to investigate the dynamics of the flood in greater detail. Still, the application of microwave brightness temperature and soil moisture products from AMSR-E employed by Bindlish et al. (2009) demonstrate their value as tools for mapping flood extent on large scale arid environments.

Ticehurst et al. (2009) combined both MODIS and passive microwave data in floodplain mapping to mitigate the disadvantages of each, citing the better spatial resolution of MODIS and AMSR-Es low sensitivity to cloud cover as factors determining their use.

This research observes a large scale flooding event using MODIS and AMSR-E data products and analyses the relationship between these two monitoring techniques, in particular the ability of each to detect surface water and observe the dynamics of the flood extent as water flows through the catchment. We use this relationship to explore where one signal can be used to compliment the other to account for errors or obscured signals. In addition, comparative analysis of both signals will be used to investigate features of the environment not immediately apparent when observed independently.

\section{STUDY AREA: COOPER CREEK}

Cooper Creek is one of the longest inland river systems in Australia (Figure 1) and also one of the most important (Kingsford et al., 1999). It is one of the few remaining river systems in Australia still largely free from anthropogenic development. Much of the available land that is developed is occupied by livestock grazing activities which support a number of rural communities in a catchment area occupying almost $300,000 \mathrm{~km}^{2}$. The catchment also supports tourism and mining operations, with substantial 

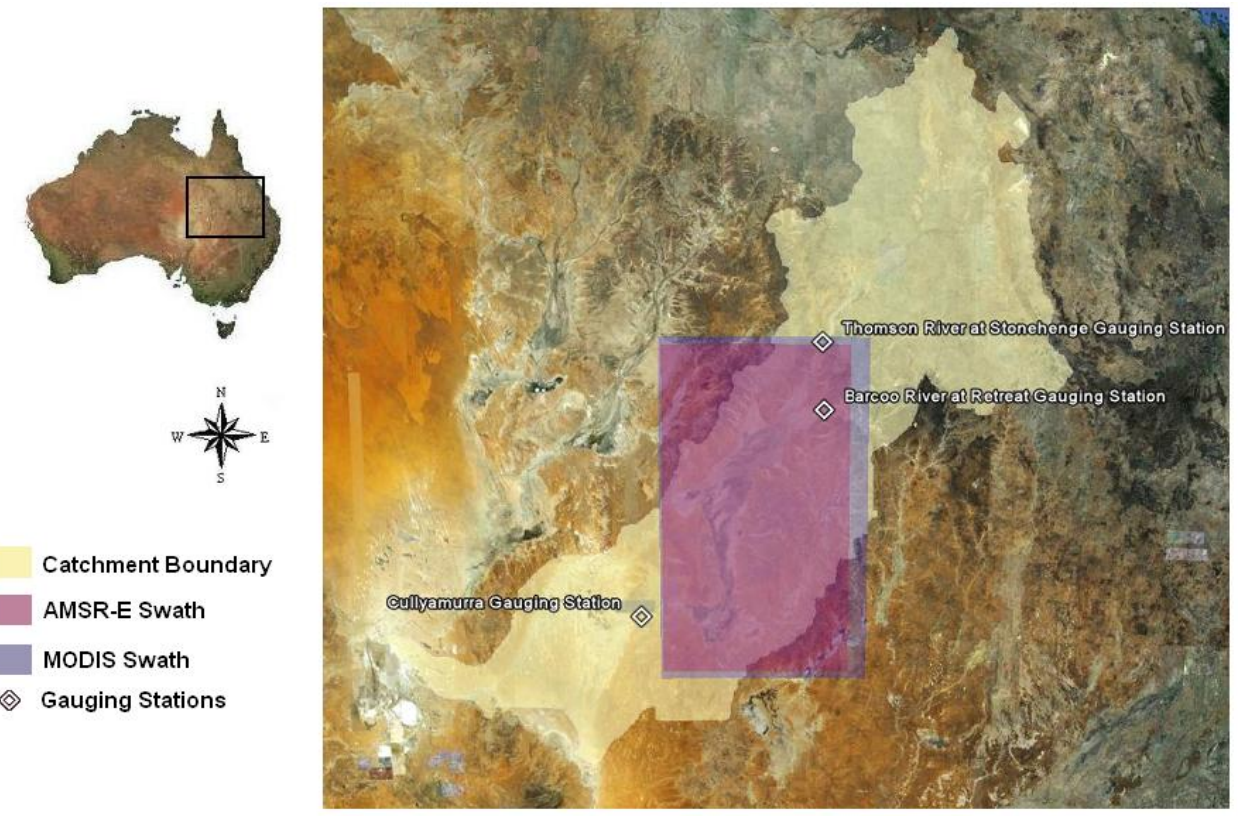

$400 \mathrm{k} \times 0$

Figure 1: Cooper Creek, Australia. Figure includes the Cooper Creek catchment boundary, as well as the satellite swath area

reserves of oil and natural gas.

Rainfall in the catchment is highly sporadic and variable with less than 400mm annually, more than half of which falls during the summer monsoon months. Long periods of drought are followed by flood events that trigger a boom in ecological growth. Ephemeral ecosystems are highly dependent on the extent of the fluvial inundation, with much of the downstream area only receiving water during years of intense flooding (Kingsford et al., 1999). This scarcity of water is compounded by large transmission losses, averaging more than 75\% (Knighton and Nanson, 1994). Knighton and Nanson (1994) also describe drainage diffusion (pooling of flood water) as one of the principal immediate causes of transmission losses throughout Cooper Creek, however these low lying, shallow pools of still water also have significant ecological value, providing a nursery for larval and juvenile fish species as well as providing feeding grounds for larger fish and birds (Arthington et al., 2005).

Kingsford et al. (1999) found that flood periods in Cooper Creek support around 1 million water birds, an indication of immense ecological value. This highly variable, erratic and seemingly hostile environment creates demanding conditions for the survival of birds and other species. Vegetation consists primarily of Acacia shrubland and ephemeral grasses that are greatly dependent on seasonal floods patterns. These environmental conditions contribute to a cornucopia of biodiversity. Many areas of the Cooper Creek catchment are recognised nationally and internationally for their ecological value, including World Heritage listings and the Ramsar Convention among others. Many rare and endemic flora and fauna species inhabiting the catchment are protected at the state and national level. Anthropogenic diversions of these flows would only put greater stress on an already fragile ecosystem (Kingsford et al., 1999).

Cooper Creek also provides a unique opportunity to compare and analyse two different methods of remote sensing. The use of MODIS in the Cooper Creek catchment is ideal, due to the nature of the water that supplies Cooper Creek. Rain that falls on the western slopes of the Great Dividing Range in CentralNorth Queensland flows through Cooper Creek en route to Lake Eyre in South Australia (Bindlish et al., 2009), travelling along slow, gentle sloping pathways. This provides a greater chance of having available cloud-free images of the floodplain area since the clouds that produce the rain are occurring in the upper catchment. 


\section{METHODOLOGY}

Daily remotely sensed data from MODIS and AMSR-E between 07-Jan-2008 and 03-Mar-2008 were observed in this research. A subsequent flood event occured within this time period. This flood event had a recurrence interval of 3 years. The relationship between MODIS and AMSR-E was examined during the flood event.

MODIS data were provided as reflectance in the visible red (VIS, band 1, 620-670nm) and near-infrared (NIR, band 2, 841-876nm) bands at $250 \mathrm{~m} \times 250 \mathrm{~m}$ resolution (MOD09GQ). Daily true colour MODIS images from the AERONET Tinga Tingana subset on NASA's MODIS Rapid Response were used to verify that there were sufficient cloud free images in this time period where a flood event was apparent. These images were provided free from NASA (2010).

As cloud cover is one of the most documented sources of error in using optical remote sensing data, such contamination could not be ignored. Cloud-affected images were removed manually through visual analysis and the remaining cloud free images were deemed sufficient to perform an appropriate analysis without having to use a cloud filtering algorithm. Once cloud free images had been obtained, Normalised Difference Vegetation Index (NDVI) was calculated. NDVI is a numerical representation of vegetation health. This is particularly useful for determining the temporal and spatial dynamics of the vegetation response during and following a flooding event. NDVI can be also used to determine inundated areas as water's reflectance is much lower than that of many land surface features (Pettorelli et al., 2005). The averaging of pixels during the downscaling process compound surface water signals with surrounding dry land, however, this is still sufficient to provide a qualitative determination of the presence of surface water. NDVI was calculated using VIS and NIR reflectance provided by MODIS using equation (1):

$$
N D V I=\frac{N I R-V I S}{N I R+V I S}
$$

AMSR-E data were provided as a VUA-NASA land surface parameter retrieval product of surface soil moisture content in $\% \mathrm{vol} / \mathrm{vol}$ at $25 \mathrm{~km} \times 25 \mathrm{~km}$ resolution based on level 2 resampled microwave brightness temperatures (Owe et al., 2008). The AMSR-E has a very shallow sampling depth, able to retrieve soil moisture from only the top $1-2 \mathrm{~cm}$ of the soil profile. Observations can encounter various errors; microwaves signals are sensitive to rainfall and AMSR-E images often contained null pixel values. Visual comparisons with MODIS data were used to identify these errors and the images were removed manually.

MODIS observations covered a larger swath and were at a much higher resolution than the AMSR-E observations $(250 \mathrm{~m}$ vs $25 \mathrm{~km})$. In order to prepare the data for comparison, the spatial extent of the MODIS and AMSR-E swaths where matched to represent the same observation area. MODIS images were cropped from 2000x1200 pixels to $1913 \times 1080$ pixels, and aligned to fit the corner coordinates of the AMSR-E data. The cropped MODIS images were then aggregated to match the resolution of the AMSR-E images at 17x11pixel. Each AMSR-E pixel covers the same area as $112 \times 98$ pixels from a MODIS image. The downscaling process calculates the average of the 112x98 MODIS pixel values that occupied the same area as a single AMSR-E pixel to create a 17x11pixel MODIS image that can be compared with an AMSR-E image (Figure 2).

Comparative analysis is focused on the areas covering pixels 6,6 (25.63S, 142.4E) and 5,7 (25.88S, 142.1E). This area was chosen for its wide channel width (approx. $30 \mathrm{~km}$ ) and on the proximity to the flow of water through the catchment to accomodate for the coarse resolution AMSR-E and minimise the errors due to averaging mixed pixels. Time-series plots were made from these pixels to compare, at a given point, how NDVI and soil moisture content change in relation to one another over the duration of the flood.

Gauge data from upstream (Stonehenge and Retreat) and downstream (Cullyamurra) of Cooper Creek were also used for analysis with remote sensing data to confirm the signals from the satellite observations were in fact related to the presence of flood waters. 


\section{RESULTS}

Figures 3 and 4 show that at the beginning of the observation period soil moisture in the surface layer is measured to be between $10 \% \mathrm{vol} / \mathrm{vol}$ and $20 \% \mathrm{vol} / \mathrm{vol}$. Towards the end of January, a sharp rise in soil moisture occurs peaking at around the $1^{\text {st }}$ of February. Concurrently, NDVI, which at the beginning of the observation period was around 0.2 , drops sharply reaching a minimum also around the $1^{\text {st }}$ of February. The gauge data from Stonehenge and Retreat show a large peak, consistent with the temporal pattern of the remote sensing signals, an indication of the presence of flood waters. Following the $1^{\text {st }}$ of February, NDVI rises again rapidly but also continues to increase. Soil moisture on the other hand, after peaking drops back down but stabilises between $10 \% \mathrm{vol} / \mathrm{vol}$ and $20 \% \mathrm{vol} / \mathrm{vol}$.

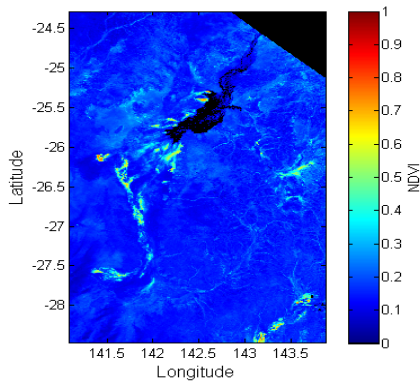

(a) 31-Jan-2008

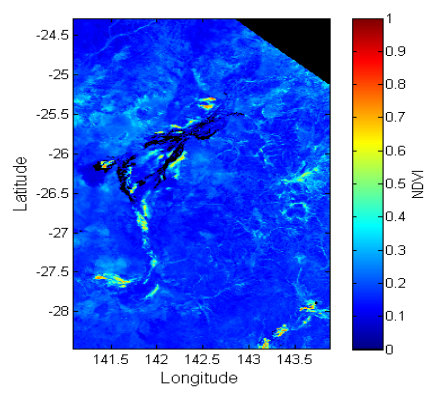

(b) 9 -Feb-2008

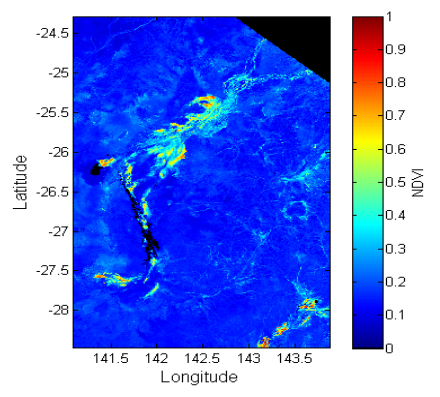

(c) $21-F e b-2008$
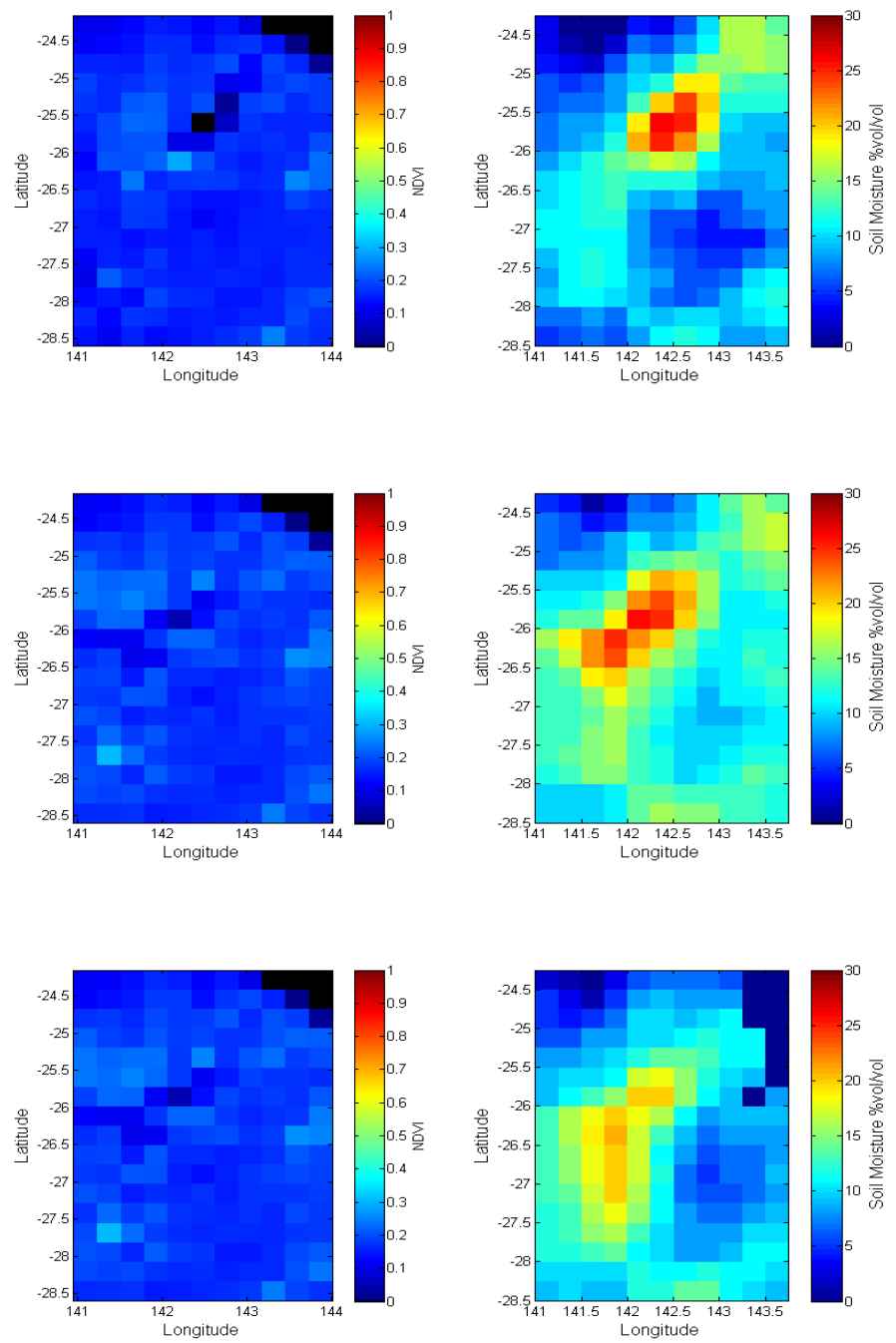

Figure 2: (L-R) NDVI MODIS image, Downscaled NDVI MODIS image, AMSR-E Soil Moisture image. Surface water is represented as black* in the MODIS images (low NDVI) and as bright red in the AMSR-E image (high soil moisture).

*An exception is the North-East corner of the MODIS image which is the boundary of the MODIS swath and consists of null values. 
The continuing rise in NDVI after the presence of water is consistent with the expected vegetation response that occurs subsequent to the flooding event. Arid regions such as Cooper Creek have characteristic boom periods following times of flood, where the abundance of water spurs the growth of seeds that had lain dormant in the soil since the last flooding event. These surges in biological productivity, though short-lived, are crucial to the health of the ecosystem.

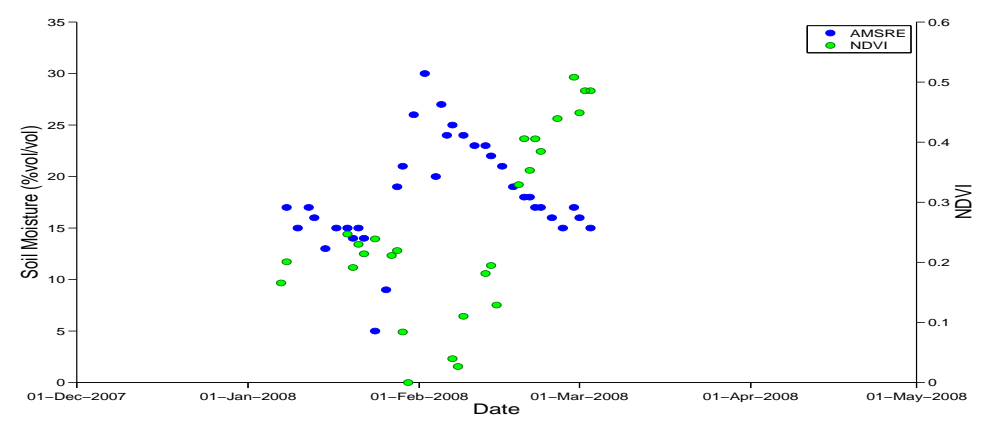

Figure 3: Time series of NDVI vs Soil Moisture Content at 25.63S, 142.4E [pixel $(6,6)]$.

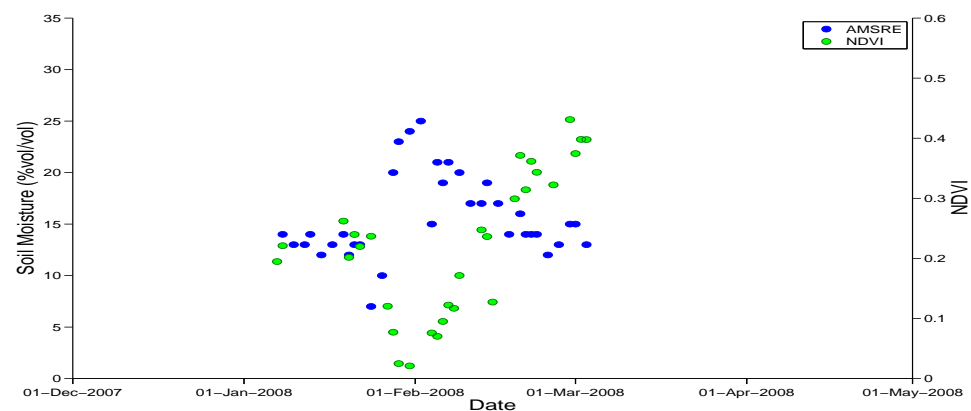

Figure 4: Time series of NDVI vs Soil Moisture Content at 25.88S, 142.1E [pixel $(5,7)$ ].

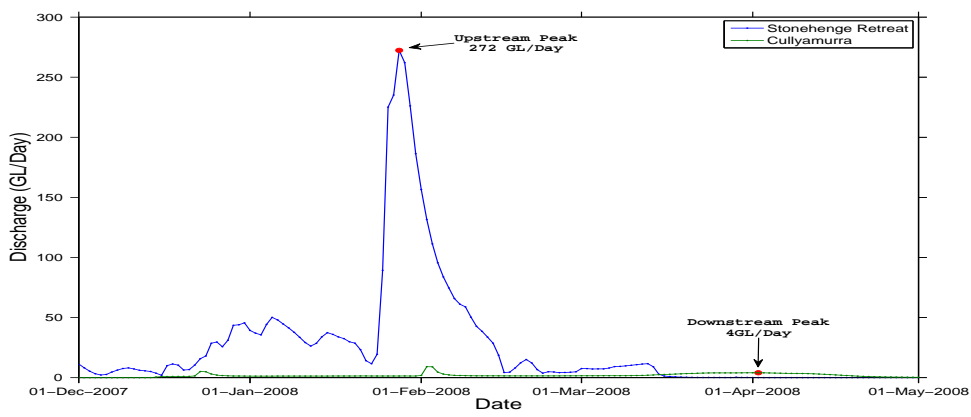

Figure 5: Discharge Upstream (Stonehenge and Retreat combined) and Downstream (Cullyamurra) of the Cooper Creek.

Downstream of Cooper Creek at Cullyamurra, a smaller peak is observed, on the $2^{\text {nd }}$ of April with a 98.5\% decrease in flow volume (Figure 5). Though there were several peaks in the Hydrograph throughout the observation period, this peak was identified as resulting from the flood peak observed on the $1^{\text {st }}$ of February. The timing of the other peaks didn't match the flood pulse as observed in the satellite data, nor the characteristic slow, anastomosing topography of Cooper Creek. Other peaks such as those observed on the $3^{\text {rd }}$ of February displayed a sharp rising and falling edge, more characteristic of runoff from a localised rain event rather than a gradual increase and decline from a slow moving flood pulse. This hydrograph apart from confirming the temporal dynamics of the flood pulse with satellite observations, illustrates the significant transmission losses and slow flow rates of Cooper Creek. 


\section{DISCUSSION AND CONCLUSION}

This study demonstrated the use of optical and passive microwave remote sensing to monitor an episodic flood event in a large scale, arid environment, Cooper Creek.

NDVI observations from MODIS were able to clearly show the flood pulse as it advances southward through Cooper Creek, as represented by the black pixels in Figure 2. The resolution was sufficient to observe the flow of water through individual flow paths. The ability of NDVI to identify surface water as well as vegetation response, make it an ideal tool for observing the relationship between the hydrology and vegetation growth from a flood event in this environment. This is represented namely in Figure $2 \mathrm{c}$ as the sharp increase is NDVI that is apparent following the passing of flood waters. However, the vegetation signal can obscure that of surface water, especially from riparian vegetation which grow near the water's surface. Figure $2 \mathrm{c}$ shows a dominant vegetation response in the upper catchment and no evidence of surface water.

AMSR-E observations, despite the coarse spatial resolution performed well at identifying the flood pulse in the upper reaches of Cooper Creek (Figure 2a). However, as the floodwaters move into the narrower $(<30 \mathrm{~km})$ sections in the lower reaches (Figure $2 \mathrm{c})$ a smearing effect is apparent. This could be the result of AMSR-E resolution being too coarse to identify areas of surface water or possibly an increased variability in soil conditions, topography and land cover, even perhaps the effect of transmission losses downstream, reducing the intensity of the soil moisture signal. Despite this uncertainty, the extent of the flood and its rate of advance can still be clearly determined using AMSR-E. A reduction in soil moisture was also observed just prior to the flood event (Figures $3 \& 4$ ). The reason for this observation could not be deduced, given the data available.

Combining microwave-derived soil moisture with NDVI improves the ability to analyse the spatial and temporal dynamics of a flood event in a large scale, arid environment; where cloud cover obscured optical sensors, cloud penetrating microwave data were used; where wet soil resultant of recent rain obscured the real flood extent, optical data sensitive only to surface water, were used to observe flood extent; poor resolution microwave signals were interpreted with higher resolution optical signals.

The time series developed in this research (Figure $3 \& 4$ ) demonstrated a clear correlation between microwave-derived soil moisture and NDVI. In the presence of surface water, soil moisture peaks, while NDVI reaches its minimum. This correlation was able to reveal other features of the relationship between the hydrology and the vegetation response following a flooding event which were not apparent when observed independently. Comparative analysis between soil moisture and NDVI observations show that once the flood had passed, vegetation growth continued despite soil moisture rapidly returning to preflood conditions, suggesting that vegetation may be drawing from water that has infiltrated deeper into the soil profile, out of the reach of the AMSR-E sensor, which can only measure soil moisture at the top $1-2 \mathrm{~cm}$ of the soil profile under light to moderate vegetation cover.

The consistency and quality of flood monitoring observations are improved by combining remote sensing techniques, along with the understanding of temporal and spatial dynamics of the hydrology and vegetation growth in large scale, arid environments.

\section{ACKNOWLEDGEMENTS}

This research was supported by the University of Melbourne, School of Engineering and the first author would like to acknowledge Kaighin McColl and Robert Luke for their valuable assistance. MODIS observations were provided by Dr Niel Sims PhD at CSIRO.

\section{REFERENCES}

Alsdorf, D. E., E. Rodriguez, and D. P. Lettenmaier (2007). Measuring surface water from space. Reviews of Geophysics. 45(2), 1-24.

Arthington, A. H., S. R. A Balcombe, G. A. A Wilson, M. C. A Thoms, and J. A Marshall (2005). Spatial and temporal variation in fish-assemblage structure in isolated waterholes during the 2001 dry season of an arid-zone floodplain river, Cooper Creek, Australia. Marine and Freshwater Research 56(1), $25-35$. 
J. Ho et al., Comparative Analysis of NDVI and Microwave-Derived Soil Moisture for Determining...

Bindlish, R., W. T. Crow, and T. J. Jackson (2009). Role of passive microwave remote sensing in improving flood forecasts. Geoscience and Remote Sensing Letters, IEEE 6(1), 112 - 116.

Irimescu, A., G. Stancalie, V. Craciunescu, C. Flueraru, and E. Anderson (2009). The use of remote sensing and GIS techniques in flood monitoring and damage assessment: A study case in Romania. In J. A. A. Jones, T. G. Vardanian, and C. Hakopian (Eds.), Threats to Global Water Security, NATO Science for Peace and Security Series C: Environmental Security, pp. 167-177. Springer Netherlands.

Kingsford, R., A. Curtin, and J. Porter (1999). Water flows on Cooper Creek in arid Australia determine 'boom' and 'bust' periods for waterbirds. Biological Conservation 88(2), 231 - 248.

Knighton, A. D. and G. C. Nanson (1994). Flow transmission along an arid zone anastomosing river, cooper creek, australia. Hydrological Processes 8(2), 137-154.

Mertes, L. A. K. (2002). Remote sensing of riverine landscapes. Freshwater Biology 47(4), 799-816.

NASA (2010). NASA Earth Observations AERONET Tinga Tingana Subset. http: // lance-modis.eosdis.nasa.gov/imagery/subsets/?project=aeronet $/$ \&subset=Tinga \_Tingana.

Owe, M., R. De Jeu, and T. Holmes (2008). Multi-sensor historical climatology of satellite-derived global land surface moisture. Journal of Geophysical Research 113.

Pettorelli, N., J. O. Vik, A. Mysterud, J.-M. Gaillard, C. J. Tucker, and N. C. Stenseth (2005). Using the satellite-derived NDVI to assess ecological responses to environmental change. Trends in Ecology \& Evolution 20(9), 503-510.

Smith, L. C. (1997). Satellite remote sensing of river inundation area, stage, and discharge: a review. Hydrological Processes 11(10), 1427-1439.

Ticehurst, C., P. Dyce, and J.-P. Guerschman (2009, July). Using passive microwave and optical remote sensing to monitor flood inundation in support of hydrologic modelling. In Anderssen, R., Braddock, R., and Newham, L. (eds), 18th World IMACS Congress and MODSIM09 International Congress on Modelling and Simulation, Cairns, Australia: Modelling and Simulation Society of Australia and New Zealand and International Association for Mathematics and Computers in Simulation: 3747-3753. 